\section{Disclosure: only a first step}

We applaud CMAJ's recent focus on the importance of disclosing conflicts of interest in medical education ${ }^{1}$ and research. ${ }^{2}$ However, disclosure is only a first step toward mitigating commercial influence, and too often it is viewed as sufficient.

For example, at the last meeting of the American Academy of Child and Adolescent Psychiatry, hundreds of presenters disclosed affiliations with commercial supporters. ${ }^{3}$ However, attendees considered the sessions "free of commercial bias," with a mean rating of $9.17 / 10$ on this item; the result was celebrated as the product of a "strong focus on conflict of interest and disclosure issues."

Simply disclosing a conflict of interest is inadequate because relationships with industry are known to influence physicians' professional behaviour, ${ }^{5}$ and the physician bias mediating the influence is largely unintentional. ${ }^{6}$ Furthermore, disclosures alone may provide false reassurance by giving the appearance that physician-industry relationships have been adequately managed. In fact, one study found that when a conflict of interest was disclosed, it had greater, not less, influence. ${ }^{6}$

We must move beyond mere disclosure of conflicts of interest toward developing additional regulatory mechanisms aimed at minimizing their pervasive influence. Like George Washington admitting that he chopped down his father's cherry tree, our willingness to disclose conflicts of interest does not absolve us of further responsibility.

\section{Elia Abi-Jaoude MSc MD}

University Health Network, University of

Toronto, Toronto, Ont.

Daniel A. Gorman MD

University of Toronto, The Hospital for

Sick Children, Toronto, Ont.

\section{REFERENCES}

1. Hébert PC, MacDonald N, Flegel K et al. Competing interests and undergraduate medical education: time for transparency. CMAJ 2010;182:1279.

2. Drazen JM, Van Der Weyden MB, Sahni P et al Uniform format for disclosure of competing interests in ICMJE journals. CMAJ 2009;181:565.

3. Program of the 5th Annual Meeting of the Ameri- can Academy of Child and Adolescent Psychiatry. Washington (DC): The Academy. 2009;183-203.

4. Ryan ND. 56th Annual Meeting evaluation results. AACAP News 2010;41:138.

5. Wazana A. Physicians and the pharmaceutical industry: Is a gift ever just a gift? JAMA 2000; 283:373-80

6. Cain DM, Detsky AS. Everyone's a little bit biased (even physicians). JAMA 2008;299:2893-5.

For the full letter, go to: www.cmaj.ca/cgi/eletters /182/12/1279\#594536

DOI:10.1503/cmaj.110-2109

\section{Advertising campaigns for cystic fibrosis}

As adults with cystic fibrosis, we have benefited greatly from the work of the Canadian Cystic Fibrosis Foundation. Thanks to the foundation's long-term investment in research and care, people with cystic fibrosis are living longer, healthier lives. However, there is still no cure - cystic fibrosis is the most common, fatal genetic disease affecting children and young adults in Canada. There remains an urgent need to support future programs to help us fight this devastating disease.

Unfortunately, in contrast to other major diseases, cystic fibrosis is not well-known or understood by Canadians. It is therefore vital that fundraising advertising campaigns present a powerful and real depiction of what it's like to live with cystic fibrosis.

Before launching an advertising campaign, the foundation consults and receives input from the cystic fibrosis community, including adults and parents of children with the disease and health care professionals. As leading members of this community who approved the current campaign, we recognize that its hard-hitting message may affect some people negatively, ${ }^{1}$ and we try very hard to minimize this impact. Thanks to the foundation, its volunteer chapters and the cystic fibrosis clinics across Canada, our community receives thoughtful communications that prepare us for each advertising campaign and explain the purpose of the campaign's message.

We strongly believe that the benefits of increasing awareness, and ultimately support, for cystic fibrosis research and care will help all people with the disease and move us closer to a world where cystic fibrosis is no longer a progressive, life-shortening disease.

\section{Nathan Fish}

Ontario representative, Adult Cystic

Fibrosis Committee, and Advertising Campaign Working Group member,

Canadian Cystic Fibrosis Foundation,

Brantford, Ont.

\section{Karen Gliddon}

Hamilton and Area Chapter President, and Adult Committee Chairperson, Executive Committee, Canadian Cystic Fibrosis Foundation, Brantford, Ont.

\section{REFERENCE}

1. Janvier A. Raising money for cystic fibrosis: At what price? [letter] CMAJ 2010;182:1079

For the full letter, go to: www.cmaj.ca/cgi/eletters /182/10/1079-a

DOI:10.1503/cmaj.110-2107

\section{Clinical guidelines may need ethical component}

The AGREE collaboration has introduced a new research-based version of its instrument to assess the quality of clinical guidelines and the reporting of the underlying development process. ${ }^{1,2}$

This version maintains the same six quality-defining domains that underpinned the original AGREE approach: scope and purpose; stakeholder involvement; rigour of development; clarity of presentation; applicability; and editorial independence. By keeping these domains, the AGREE collaborators seem to imply that they do not consider an extension necessary.

Perhaps the guidelines (and tools) should explicitly help their users put the clinical guidance offered into practice in ethically competent ways. As acknowledged in the CanMEDS framework, ${ }^{3}$ health care professionals need robust ethical competence to provide patient care. This is not only relevant in dramatic life-or-death situations, but also in the increasingly complex reality of everyday practice, where potential issues are usually less striking but far more common and often no less important. $^{4}$ 